\title{
CONHECIMENTO DE PAIS E CUIDADORES SOBRE SAÚDE BUCAL DE CRIANÇAS PRÉ-ESCOLARES
}

\author{
Elaine Roberta Leite de Souza, Jéssica Fernanda Delfino dos San- \\ tos, Abrahão Alves de Oliveira-Filho, Maria Angélica Sátyro Go- \\ MES Alves
}

\begin{abstract}
Resumo: Este estudo analisou conhecimentos de saúde bucal de pais e cuidadores de crianças de 3 creches do município de Patos/PB, atendidas pelo projeto de extensão Construindo Sorrisos. A amostra foi de 107 indivíduos. Os resultados, mostraram que $74,77 \%$ destes já receberam informações sobre higiene bucal e alimentação, $100 \%$ considerando-as importantes. $85,05 \%$ relataram que seus filhos escovam os dentes diariamente predominando a frequência de 2 vezes ao dia (83,52\%). 78,50\% falaram que as crianças ingerem alimentos açucarados, sendo que, 64,29\% ingeremnos diariamente. $70,09 \%$ relataram que as crianças tomam leite antes de dormir e em $77,33 \%$ dos casos é adicionado açúcar. $78,67 \%$ não escovam os dentes após esta refeição e $94,31 \%$ nunca visitou o dentista. Conclui-se que, embora os pais e educadores importem-se e tenham conhecimento sobre saúde bucal, a maioria permanece com maus hábitos em relação à saúde bucal, refletidos em escovações insuficientes e ausência da ida ao dentista.
\end{abstract}

Palavras-chave: Saúde bucal. Educação infantil. Promoção de saúde.

KNOWLEDGE OF PARENTS AND ACCOUNTABLE ABOUT ORAL HEALTH OF PRE-SCHOOL CHILDREN

Abstract: This study analyzed oral health knowledge of parents and caregivers of
children from 3 daycare centers in the municipality of Patos in the state of Paraíba,
attended by the extension project Construindo Sorrisos. The sample consisted of 107
individuals. The results showed that $74.77 \%$ of them already received information
about oral hygiene and nutrition, $100 \%$ considering them as important. $85.05 \%$
reported that their children brush their teeth daily, predominating the frequency 
of twice a day (83.52\%). $78.50 \%$ said that children eat sugary food, with $64.29 \%$ ingesting them daily. $70.09 \%$ reported that children drink milk before bedtime and from $77.33 \%$ of these cases sugar is added. $78.67 \%$ do not brush their teeth after this meal and $94.31 \%$ have never visited the dentist before. It is concluded that, although parents and educators matter and that they are aware of oral health, most of them still have poor habits regarding oral health, reflected in poor brushing and the absence of going to the dentist.

Keywords: Oral health; Early childhood education; Health Promotion.

CONOCIMIENTO DE PADRES Y CUIDADORES SOBRE SALUD BUCAL DE NIÑOS PRE-ESCOLARES

Resumen: Este estudio analizó conocimientos de salud bucal de padres y cuidadores de niños de 3 guarderías del municipio de Patos / PB, atendidas por el proyecto de extensión Construyendo Sonrisas. La muestra fue de 107 individuos. Los resultados, mostraron que el $74,77 \%$ de éstos ya recibieron informaciones sobre higiene bucal y alimentación, 100\% considerándolas importantes. El 85,05\% relató que sus hijos cepillaban los dientes diariamente predominando la frecuencia de 2 veces al día (83,52\%).78,50\% habló que los niños ingieren alimentos azucarados, siendo que el $64,29 \%$ ingeren diariamente.70,09\% relató que los niños toman leche antes de dormir y en el $77,33 \%$ de los casos se añade azúcar.78,67\% no cepillaba los dientes después de esta comida y el $94,31 \%$ nunca visitó al dentista. Se concluye que, aunque los padres y educadores se importan y tienen conocimiento sobre salud bucal, la mayoría permanece con malos hábitos en relación a la salud bucal, reflejados en cepillados insuficientes y ausencia de la ida al dentista.

Palabras-clave: Salud bucal. Educación Infantil. Promoción de la salud.

\section{INTRODUÇÃo}

O último levantamento epidemiológico realizado pelo Ministério da Saúde no ano de 2010 trouxe consigo dados alarmantes sobre a saúde bucal da população brasileira. Apesar dos visíveis avanços na área da saúde, as patologias bucais ainda representam um grave problema de saúde pública. Tais dados são ainda mais preocupantes nas regiões Norte, Centro-oeste e Nordeste do Brasil, onde os índices ceo-d (dentes cariados, extração indicada ou obturados) e periodontopatias (gengivite e periodontite) são os maiores quando comparados com outras regiões (SB BRASIL, 2012). A persistência dessa realidade 
brasileira motivou a mudança do modelo curativo para o assistencial preventivo, tendo como base a Constituição Federal de 1988 e Lei Orgânica da Saúde 8.080, de 1990 onde foi estabelecido o dever do Estado na implantação de atividades de promoção e prevenção de saúde. Desta maneira a motivação e a educação tornam-se ferramentas de grande importância para a mudança de hábitos dos indivíduos sendo essenciais para a obtenção e manutenção de saúde (BRASIL, 1988; BRASIL, 1990).

A educação em saúde compreende um conjunto de práticas que proporcionam a construção de um espaço de troca de conhecimentos, objetivando a mudança de hábitos individuais ou coletivos buscando melhorias na qualidade de vida. Já a Promoção de Saúde, de acordo com a Organização Pan-americana de Saúde - OPAS (1995) é caracterizada por ser multidisciplinar e integral considerando aspectos familiares, sociais e ambientais. Desta forma, as ações de promoção de saúde devem buscar favorecer o aprendizado de métodos de prevenção e incorporação de hábitos saudáveis (PELICIONE et al.,1999) A fase pré-escolar é caracterizada por ser a ideal para a implantação dessas práticas, pois segundo Nunes e Brenda (2005) é nessa fase em que se estabelecem as bases do aprendizado, sendo assim, a ideal para a implantação e desenvolvimento de programas educativo-preventivos, pois a facilidade de aprendizado, contribui para as modificações de hábitos de higiene e a motivação, nessa fase tão peculiar, tornando tais mudanças permanentes. (NUNES; BRENDA, 2005).

Outro fator determinante ligado à incorporação de hábitos saudáveis são as relações interpessoais. Na infância, as crianças aprendem através da interação com o meio social e físico em que estão inseridas e seus hábitos, valores e atitudes são diretamente influenciadas por esse meio (KOBARG et al., 2006; REGO, 2011). Apesar da susceptibilidade de acometimento das afecções bucais nessa fase, tais condições podem ser evitadas com a implantação precoce e manutenção de hábitos de higiene oral e alimentação saudável (ISMAIL, 1998). Nesse contexto, os pais e responsáveis, considerados como os principais sistemas de apoio da criança, constituem-se como referência para o ensino de práticas relacionadas a saúde (SOARES et al., 2013; MARCARINI et al., 2010).

A extensão universitária desencadeia um processo de transformação da sociedade e universidade instaurando uma via de "mão dupla" em que há simultaneamente a troca de conhecimentos acadêmico-científicos e experiências vividas sendo fundamentada pela inter-relação entre a pesquisa, o ensino e a extensão (SERRANO, 2001; MINISTÉRIO DA EDUCAÇÃO, 2007). O 
Projeto de extensão Construindo Sorrisos vinculado a Unidade Acadêmica de Ciências Biológicas - UACB/CSTR e Pró-Reitoria de Pesquisa e Extensão - PROBEX/FLUEX-UFCG, vem sendo desenvolvido desde o ano de 2015 e tem como principal objetivo a realização de ações de promoção de saúde bucal com crianças, pais e educadores de escolas públicas de ensino infantil no município de Patos-PB. Para isso, são realizadas atividades de promoção de saúde, evidenciação de placa, escovação supervisionada, e orientação de cardápio alimentar. Os pais e professores recebem esclarecimentos sobre as principais doenças que podem acometer a cavidade bucal das crianças através de palestras e rodas de conversa assim como orientações sobre alimentação saudável e o uso racional do açúcar.

Desta maneira, os conhecimentos dos pais e cuidadores sobre saúde bucal atuam diretamente na prevenção das afecções que acometem a boca e é determinante para a saúde das crianças. A implantação de projetos extensionistas, como o Construindo Sorrisos, corrobora a educação em saúde, tornando-se fundamental para a melhoria dos hábitos de higiene oral e da saúde de todos os envolvidos trazendo benefícios tanto para os alunos quanto para a comunidade. Baseado no exposto, o presente estudo teve como objetivo analisar os conhecimentos de saúde bucal de pais e cuidadores de crianças em idade pré-escolar de 3 creches do município de Patos, PB.

\section{Metodologia}

Trata-se de um estudo descritivo transversal que utilizou a entrevista como meio para a coleta dos dados onde buscou analisar os conhecimentos de pais e cuidadores acerca da saúde bucal de crianças em idade pré-escolar. A amostra foi composta por 107 pais e cuidadores, cujas crianças estudavam nas creches municipais Cremilde Bezerra (42), Glauce Burity (28) e Santina do Gelo (36) no município de Patos - PB, que eram atendidas pelo projeto de extensão Construindo Sorrisos na vigência de 2017.

O instrumento utilizado para a coleta de dados foi um questionário semiestruturado aplicado por meio de entrevista, nos meses de julho a novembro de 2017, o qual continha 15 perguntas objetivas que abordavam questões sobre alimentação saudável, hábitos de higiene bucal e por fim, a avaliação do projeto Construindo Sorrisos. 
A coleta de dados foi realizada por 10 alunos do curso de graduação em Odontologia da Universidade Federal de Campina Grande - UFCG, que eram integrantes do projeto de extensão universitária Construindo Sorrisos, sendo estes orientados por dois professores do curso. Os pais e responsáveis eram abordados ao virem deixar as crianças nas respectivas creches e somente após concordarem participar, a entrevista era realizada.

Para a análise dos dados, foi utilizado o software Excel $^{\circ} 2010$ e expressos através de estatística descritiva, em frequências relativas. Para melhor descrição dos resultados, as respostas obtidas com questionário foram divididas em três partes:

1. Distribuição dos pais e cuidadores por gênero e idade;

2. Hábitos de higiene oral das crianças e hábitos alimentares;

3. Avaliação do projeto de extensão Construindo Sorrisos e conhecimento dos pais e cuidadores acerca dos serviços oferecidos pela clinica escola de odontologia da Universidade Federal de Campina Grande - UFCG.

\section{REsultados}

A amostra do estudo consistiu em 107 pais ou cuidadores de crianças em idade pré-escolar que eram atendidas pelo projeto de extensão Construindo Sorrisos na vigência do ano de 2017. Quanto as características pessoais da amostra, 100\% eram do gênero feminino, com a faixa etária variando entre 20 e 56 anos, com uma média de 34,2 anos (tabela 1).

TABELA 1 - Distribuição dos pais e cuidadores por gênero e idade.

\begin{tabular}{|c|c|c|c|}
\hline Variáveis & & $\mathbf{N}$ & $\%$ \\
\hline \multirow{2}{*}{ Gênero } & Feminino & 107 & $100 \%$ \\
& Masculino & 0 & $0 \%$ \\
\hline & & & \\
& & 21 & $19,63 \%$ \\
\hline Idade & 25 anos & 22 & $20,56 \%$ \\
& $30-40$ anos & 39 & $36,45 \%$ \\
& $40-50$ anos & 17 & $15,89 \%$ \\
\hline TOTAL & $>50$ anos & 8 & $7,48 \%$ \\
\hline
\end{tabular}

Acerca dos dados obtidos sobre saúde bucal e alimentação, quando os pais ou cuidadores foram questionados se já haviam recebido informações sobre 
higiene bucal e alimentação saudável 74,77\% afirmaram que sim e 100\% dos entrevistados acham que tais informações são importantes. Quanto ao hábito de escovação $85,05 \%$ dos pais ou cuidadores relataram que seus filhos escovam os dentes todos os dias e destes, houve uma predominância na frequência de 2 vezes ao dia (tabela 2$)(83,52 \%)$.

Do total, $78,50 \%$ dos pais e cuidadores relataram que as crianças ingerem alimentos ou bebidas açucaradas, sendo que destes, 64,29\% fazem o consumo diário de alimentos ou bebidas açucaradas. Foi visto também que 70,09\% dos pais ou cuidadores declararam que as crianças tomam leite/mamadeira antes de dormir e que em $77,33 \%$ há adição de açúcar. Relataram ainda que em $78,67 \%$ dos casos, não escovam os dentes após esse leite (antes de dormir). Quanto a ida da criança ao dentista, 94, \% dos pais relataram que nunca levaram seus filhos a uma consulta com o dentista (tabela 2).

TABELA 2 - Distribuição dos pais e cuidadores de acordo com as respostas dadas acerca dos hábitos de higiene oral das crianças e alimentares

\begin{tabular}{|c|c|c|c|}
\hline Perguntas & Alternativas & $\mathbf{N}$ & $\%$ \\
\hline $\begin{array}{c}\text { Já recebeu informações sobre a importância } \\
\text { da higiene bucal e da alimentação saudável } \\
\text { antes? }\end{array}$ & $\begin{array}{l}\text { Sim } \\
\text { Não }\end{array}$ & $\begin{array}{l}80 \\
27\end{array}$ & $\begin{array}{l}74,77 \% \\
25.23 \%\end{array}$ \\
\hline $\begin{array}{c}\text { Acha importante receber essas informações } \\
?\end{array}$ & $\begin{array}{l}\text { Sim } \\
\text { Não }\end{array}$ & $\begin{array}{c}107 \\
0\end{array}$ & $\begin{array}{l}100 \% \\
0 \%\end{array}$ \\
\hline Seu filho escova os dentes todos os dias? & $\begin{array}{l}\text { Sim } \\
\text { Não }\end{array}$ & $\begin{array}{l}91 \\
16\end{array}$ & $\begin{array}{l}85,05 \% \\
14,95 \%\end{array}$ \\
\hline Com que frequência? & $\begin{array}{c}1 \text { vez } \\
2 \text { vezes } \\
3 \text { ou mais vezes }\end{array}$ & $\begin{array}{c}10 \\
76 \\
5\end{array}$ & $\begin{array}{c}10.99 \% \\
83,52 \% \\
5,49 \%\end{array}$ \\
\hline $\begin{array}{l}\text { Seu filho tem o hábito de comer ou beber } \\
\text { alimentos açucarados ou balas? }\end{array}$ & $\begin{array}{l}\text { Sim } \\
\text { Não }\end{array}$ & $\begin{array}{l}84 \\
23\end{array}$ & $\begin{array}{l}78,50 \% \\
21,50 \%\end{array}$ \\
\hline Com que frequência? & $\begin{array}{l}\text { Todos os dias } \\
\text { Frequentemente } \\
\text { Nunca }\end{array}$ & $\begin{array}{l}54 \\
28 \\
25\end{array}$ & $\begin{array}{l}64,29 \% \\
33,33 \% \\
29,76 \%\end{array}$ \\
\hline $\begin{array}{c}\text { Seu filho toma leite ou mamadeira antes de } \\
\text { dormir? }\end{array}$ & $\begin{array}{l}\text { Sim } \\
\text { Não }\end{array}$ & $\begin{array}{l}75 \\
32\end{array}$ & $\begin{array}{l}70.09 \% \\
29,91 \%\end{array}$ \\
\hline Usa açúcar no leite ou mamadeira? & $\begin{array}{l}\text { Sim } \\
\text { Não }\end{array}$ & $\begin{array}{l}58 \\
17\end{array}$ & $\begin{array}{l}77,33 \% \\
22,67 \%\end{array}$ \\
\hline $\begin{array}{c}\text { Escova os dentes após esse leite (antes de } \\
\text { dormir)? }\end{array}$ & $\begin{array}{l}\text { Sim } \\
\text { Não }\end{array}$ & $\begin{array}{l}16 \\
59\end{array}$ & $\begin{array}{l}21,33 \% \\
78,67 \%\end{array}$ \\
\hline Seu filho já foi ao dentista? & $\begin{array}{l}\text { Sim } \\
\text { Não }\end{array}$ & $\begin{array}{c}6 \\
101\end{array}$ & $\begin{array}{l}5,61 \% \\
94,39 \%\end{array}$ \\
\hline
\end{tabular}


Quantas vezes seu filho foi ao dentista?

\begin{tabular}{|c|c|c|}
\hline O vez & 101 & $94,39 \%$ \\
\hline 1 vez & 6 & $5,61 \%$ \\
\hline & 107 & $100 \%$ \\
\hline
\end{tabular}

TOTAL

$100 \%$

Dos dados obtidos sobre a avaliação do projeto de extensão universitária Construindo Sorrisos, $61,68 \%$ não tinham conhecimento dos serviços ofertados pela Clínica-Escola de Odontologia da UFCG, mas 100\% procuraria os serviços após o conhecimento. Do total, $100 \%$ dos pais ou cuidadores entrevistados avaliaram o projeto Construindo Sorrisos como "Ótimo", porém, apenas $26,17 \%$ perceberam mudanças nos hábitos de higiene bucal e alimentação de seus filhos após o projeto (tabela 3).

TABELA 3 - Distribuição dos pais e cuidadores referentes as respostas dadas aos quesitos sobre a Avaliação do projeto de extensão Construindo Sorrisos e conhecimento acerca dos serviços oferecidos pela clínica-escola de Odontologia da Universidade Federal de Campina Grande-UFCG.

\begin{tabular}{|c|c|c|c|}
\hline Perguntas & Alternativas & $\mathbf{N}$ & $\%$ \\
\hline $\begin{array}{c}\text { Conhece os serviços oferecidos pela Clínica- } \\
\text { Escola de Odontologia da UFCG? }\end{array}$ & $\underset{\text { Não }}{\text { Sim }}$ & $\begin{array}{l}41 \\
66\end{array}$ & $\begin{array}{l}38,32 \% \\
61,68 \%\end{array}$ \\
\hline Após saber de tais serviços, procuraria estes? & $\begin{array}{l}\text { Sim } \\
\text { Não }\end{array}$ & $\begin{array}{c}107 \\
0\end{array}$ & $\begin{array}{c}100 \% \\
0 \%\end{array}$ \\
\hline $\begin{array}{c}\text { Como avalia o projeto de extensão universitária } \\
\text { Construindo Sorrisos? }\end{array}$ & $\begin{array}{l}\text { Ruim ou péssimo } \\
\text { Regular } \\
\text { Bom } \\
\text { Ótimo }\end{array}$ & $\begin{array}{c}0 \\
0 \\
0 \\
107\end{array}$ & $\begin{array}{c}0 \% \\
0 \% \\
0 \% \\
100 \%\end{array}$ \\
\hline $\begin{array}{c}\text { Percebeu alguma mudança nos hábitos de } \\
\text { higiene e alimentação do seu filho após este } \\
\text { projeto? }\end{array}$ & $\begin{array}{l}\text { Sim } \\
\text { Não }\end{array}$ & $\begin{array}{l}28 \\
79\end{array}$ & $\begin{array}{l}26,17 \% \\
73,83 \%\end{array}$ \\
\hline TOTAL & & 107 & $100 \%$ \\
\hline
\end{tabular}

\section{Discussão}

A saúde de uma população é determinada pelas condições do meio no qual ela está inserida sendo os relacionamentos interpessoais e familiares fundamentais para o desenvolvimento biopsicossocial das crianças (KOBARG et al., 2006; REGO, 2011). Novak et al. (2011), discutem que a saúde das crianças é influenciada por vários fatores englobando fatores socais, psicológicos e ambientais. Os pais e cuidadores são o principal exemplo para as crianças nessa fase. Assim, os conhecimentos e a importância dada aos aspectos relacionados a saúde bucal e 
alimentação saudável dos pais ou responsáveis tem a capacidade de influenciar diretamente na saúde das crianças (GUARIENTI et al., 2009).

Segundo Guarienti et al., (2009), a saúde é multifatorial e engloba a inter-relação família, cultura, estrutura social e desenvolvimento físico. Assim, ações de promoção de saúde bucal direcionadas à primeira infância devem priorizar a educação dos pais, favorecendo a implantação de hábitos.

$\mathrm{Na}$ análise dos dados encontrados nesta pesquisa foram avaliados a idade e gênero dos participantes, e se pode observar uma prevalência da faixa etária de 20 a 56 anos com uma média de 34,2 anos, sendo o gênero feminino responsável por $100 \%$ deles. Tais resultados entram em conformidade com os achados nos estudos de Patrocínio e Bortolin (2014), onde foi visto que 82\% dos entrevistados eram do gênero feminino e Nagarajappa et al (2013), onde obteve-se que $62,4 \%$ dos participantes do seu estudo pertenciam a este mesmo gênero. Segundo eles, tal resultado está relacionado ao maior interesse das mães em assumir responsabilidades sob o filho.

Os resultados apontam que a maioria dos participantes do estudo já teve acesso às informações sobre saúde bucal e alimentação saudável (74,77\%), porém é importante ressaltar que um grande número de pessoas relatou não ter recebido nenhum tipo de informação. Tais dados conferem com o estudo de Massoni et al., (2010). Em seu estudo, intitulado "Saúde Bucal Infantil: Conhecimento e Interesse de Pais e Responsáveis" foram entrevistados 49 pais e responsáveis de crianças que eram atendidas pela clínica de Cariologia do Centro de Ciências da Saúde da Universidade Federal da Paraíba buscando avaliar seus conhecimentos sobre saúde oral infantil. Entre os resultados encontrados, percebeu-se que a grande maioria dos entrevistados já haviam recebido algum tipo de informação sobre saúde bucal.

Outro estudo, publicado por Oliveira e Uemura (2016), teve como objetivos avaliar a prevalência de cárie dentária em crianças de dois a quatro anos de idade das creches públicas de um município do interior da Bahia e avaliar o conhecimento sobre saúde bucal dos seus responsáveis. Para isso, foi realizada a avaliação bucal de 279 crianças e seus responsáveis responderam a um questionário contendo questões relativas ao conhecimento sobre saúde bucal. Como resultados puderam observar que a maioria dos participantes do estudo já tinha obtido informações sobre saúde bucal, porém, apesar de seus conhecimentos, estes não eram aplicados visto pela alta prevalência de carie nas crianças. 
Acerca da importância de tais informações, 100\% dos entrevistados pelo projeto de extensão universitária Construindo Sorrisos a consideram importante, também entrando em conformidade com o estudo de Massoni (2010) que também observou que os participantes do seu estudo acham que receber as informações acerca da saúde bucal são importantes.

Em seu estudo, Sabrina et al. (2016) analisou o conhecimento sobre os cuidados bucais dos cuidadores primários das crianças atendidas na clínica de Odontopediatria de uma faculdade no sul do Brasil e sua relação com a prevalência e severidade de cárie e com a condição periodontal (gengivite) dessas crianças. Para isso, realizou a aplicação de um questionário semiestruturado aos pais e/ou responsáveis de crianças em idade entre 0 e 6 anos, e como resultado, obteve que $80 \%$ dos cuidadores realizavam a limpeza dos dentes da criança diariamente e que 58,2\% fazem mais de duas vezes ao dia. A primeira porcentagem concorda com o presente estudo, no qual 85,5\% dos pais responderam que o filho escovava os dentes todos os dias. Ao que se trata da frequência de escovação os dados se conflitam onde $83,52 \%$ dos pais responderam que a criança escova os dentes 2 vezes ao dia.

Um grupo de 69 crianças com idades variando entre um e cinco anos foi estudado por Scalioni et al. (2012) onde a prevalência de cárie era de 87\%. Dentre as 60 crianças afetadas por cárie dental, foi observado que a ingestão diária de carboidrato era muito alta quando comparado às crianças sem cárie. Uma análise detectou que os alimentos e as bebidas consumidas com mais frequência pelas crianças eram pão, biscoito, macarrão, doces, achocolatados e suco, além de "salgadinhos" que frequentemente eram consumidos entre as refeições principais. Esses dados confirmam os números presentes neste estudo onde $78 \%$ dos pais afirmam que seus filhos tem o hábito de comer ou beber alimentos açucarados ou balas e 64,29\% afirmam ainda que esse consumo é diário. Junior et al. (2015) dizem ser necessário entender que o modelo atual de família apresenta hábito alimentar bastante alterado e composto basicamente de açúcares e alimentos industrializados.

Uma declaração da Academia Americana de Odontopediatria - AAPD, aponta que há um grande e devastador risco de cárie por aleitamento materno para crianças que são alimentadas ao seio e também com mamadeira, relacionando este risco a alimentação prolongada e repetitiva sem a monitorização das formas corretas de higienização oral (RIBEIRO et al, 2004). Concordando assim com este estudo onde $78,67 \%$ das crianças não escovam os dentes após 
tomar o leite/mamadeira. Logo, a Academia Americana de Pediatria considera que as crianças que dormem com mamadeira ou mamam no peito durante a noite são de alto risco para o desenvolvimento da cárie. O presente estudo mostra que 70,09\% das crianças tomam leite/mamadeira antes de dormir. Esse resultado se aproxima dos dados do estudo de Alcântara et al. (2001) que buscou analisar quais são os fatores associados a ocorrência de cárie dentaria em crianças em idade pré-escolar. Para isso, realizou a avaliação oral de 132 crianças e aplicou um questionário aos pais. Dentre os dados obtidos com o estudo, foi visto que os pais relataram que $83,5 \%$ das crianças ingeriam rotineiramente mamadeira noturna na idade pré-escolar.

Figueiredo (1998) ressalta a importância de se dar atenção especial aos hábitos alimentares nas estratégias de prevenção a cárie, pois quando uma dieta é rica em sacarose ocorre uma modificação na composição do biofilme. Ou seja, o fato de $77,33 \%$ das crianças participantes deste estudo tomarem leite/ mamadeira noturna com adição de açúcar e de não se realizar a higienização bucal após esse leite $(78,67 \%)$ aumenta significativamente o potencial de desenvolvimento de cárie na idade pré-escolar.

A cárie dentária é a infecção oral mais comum no mundo (JEON et al., 2011). Sendo a remoção mecânica do biofilme, o principal fator para a prevenção da cárie e da gengivite (WIGEN et al., 2014; AMINABADI et al., 2014; BROFFITT et al., 2013). Navarro (2014) diz que a higiene bucal em crianças até 10 anos de idade é de responsabilidade dos cuidadores primários, por isso é essencial que os pais compreendam a sua importância e sejam capazes de mantê-la, como parte da saúde geral de si e de seus filhos.

A atenção odontológica precoce é uma das ferramentas mais eficientes para reduzir a probabilidade de desenvolver doenças bucais como a cárie e periodontopatias. De acordo com a Academia Americana de Odontopediatria - AAPD (2004), é recomendado que a criança seja vista por um cirurgião-dentista dentro de 6 meses de erupção do primeiro dente primário e até 12 meses de idade visto que essas intervenções iniciais servem para auxiliar os pais acerca da higiene oral e prevenção de lesões bucais (SÁNCHEZ et al., 1997). Porém, os resultados encontrados demonstram que $94,39 \%$ dos pais e cuidadores nuncam tinham levado seu filho ao dentista, revelando que durante a fase pré-escolar uma grande parte dos pais acredita que o acompanhamento odontológico realizado pelo cirurgião-dentista não se faz necessário. Tal resultado confere com os estudos de Kramer et al. (2008), onde avaliou 
1.092 crianças entre 0 a 5 anos e pode observar que $86,7 \%$ da amostra nunca tinha ido a uma consulta odontológica.

Dados da Pesquisa Nacional por Amostragem de Domicílios (PNAD) realizada no ano de 2008 demonstrou que houve um aumento na porcentagem de crianças de 0 a 4 anos que tinham ido ao dentista quando comparado com o ano de 2003 (22,1\% e 18,1\% respectivamente). Esse aumento torna-se ainda mais significativo quando comparado com os dados obtidos no ano de 1998, em que apenas 14,4\% das crianças nessa faixa etária tinham ido ao dentista. Tais dados são ainda mais alarmantes nas regiões Norte e Nordeste que apresentaram em ambos os estudos os piores índices, verificados pelo menor percentual de crianças que visitaram o dentista. Kramer et al., (2008) ainda ressalta a necessidade de reorganização das políticas públicas de promoção de saúde que visem facilitar o acesso aos serviços de saúde.

Segundo Campezatto e Nunes (2007), a Clínica Escola objetiva proporcionar o desenvolvimento de ações e procedimentos que viabilizem o ensino e a pesquisa, colaborando para a formação do aluno de forma ética e científica, ao mesmo tempo em que beneficia a comunidade oferecendo serviços gratuitos ou de baixo custo. Um dos dados obtidos nesse estudo foi que apenas 38,32\% dos pais conheciam os serviços ofertados pela Clínica Escola de Odontologia da UFCG. Isso demonstra que uma grande parte da população desconhece tais serviços. Tal resultado também revela a importância da divulgação em uma comunidade e reforça a necessidade de introdução projetos extensionistas visto que tais projetos objetivam o fortalecimento do elo entre a comunidade e a universidade que dá aos seus alunos meios de aplicar os conhecimentos adquiridos enquanto promove as melhorias na saúde tanto geral quanto bucal dos indivíduos integrantes da comunidade atendida. Porém, quando questionados se procurariam tais serviços após o conhecimento destes, 100\% afirmou que sim. Dessa maneira, a Clínica Escola pode atender as necessidades da comunidade tanto de forma preventiva como curativa melhorando a qualidade de vida das pessoas.

Alguns dos objetivos do Projeto de Extensão Construindo Sorrisos eram fortalecer o laço universidade-comunidade, promover atividades educativas com crianças, pais e professores e divulgar os serviços prestados pela Clínica Escola de Odontologia da UFCG. Podemos dizer que tais objetivos foram alcançados já que $100 \%$ dos entrevistados consideraram os Projeto como "ótimo". Entretanto, apesar de tal resultado, constatou-se que apenas $26,17 \%$ dos 
pais e responsáveis notaram mudanças nos hábitos de higiene oral e alimentação nas crianças. Tal dado pode ser explicado pela idade das crianças, já que estas tinham a faixa etária variando de 0 a 5 anos. Brasil (1998) afirma que nessa fase as crianças aprendem pela observação e imitação, sendo importante que ela presencie adultos e outras crianças fazendo sua higiene bucal, e desta maneira, ampliem seus conhecimentos sobre tais. Segundo Soares et al. (2013), nessa idade os hábitos das crianças são diretamente influenciados pelas suas relações pessoais. Nesse contexto, torna-se necessário que os pais e responsáveis hajam como multiplicadores de saúde e estimulem diariamente a mudança de comportamento nas crianças.

\section{CONClusão}

Conclui-se, portanto, que apesar dos pais e cuidadores serem esclarecidos sobre a importância da higiene bucal e acharem as informações acerca dela importantes e em como a alimentação interfere na qualidade da saúde bucal dos seus filhos, os mesmos não aplicam de forma correta estes conhecimentos no contexto diário visto que os maus hábitos de alimentação e higiene ainda predominam. Tal fato é refletido na alimentação com adição constante de açúcar e na higienização com periodicidade inferior a considerada suficiente para um correto e eficiente controle do biofilme dental.

No entanto, ainda é notório o desinteresse por parte dos pais em levar seus filhos para consultas preventivas e/ou curativas nessa faixa etária, ressaltando assim que apesar de tal importância e de concordar com a mesma, esse passo ainda é um ponto negativo. Isso demonstra a necessidade de se intensificar ações de educação, promoção e motivação em saúde, principalmente para os pais e cuidadores das crianças, auxiliando na melhora da qualidade de vida.

\section{REFERÊNCIAS}

ÂlCANTARA, T. L.; BATISTA, M. J.; GIBILINI, C.; FERREIRA, N. P.; SOUSA, M. L. R. R. P. G. Fatores associados à saúde bucal de pré-escolares inseridos em programa educativo preventivo no município de Piracicaba/SP. RPG Rev Pós Grad, Piracicaba/SP, 18(2), 7-102, 2011. Disponível em: http://www.fo.usp.br/wp-content/uploads/Fatores-associados-\%C3\%A0-sa\%C3\%BAde-bucal-de-pr\%C3\%A9-escolares-inseridos-em-programa-educativo-preventivo-no-munic\%C3\%ADpio-de-Piracicaba_SP.pdf. 
American Academy of Pediatric Dentistry. Clinical guideline on infant oral health care. Pediatr Dent. 2004;26(Suppl 7):67-70.

AMINABADI, N. A.; GHOREISHIZADEH, A.; GHOREISHIZADEH, M.; OSKOUEI, S. G.; GHOJAZADEH, M. Can child temperament be related to early childhood caries? Caries Res., 2014; 48: 3-12. URL: https://doi.org/10.1159/000351636

Brasil. Ministério da Saúde. Secretaria de Atenção à Saúde. Secretaria de Vigilância em Saúde. SB Brasil 2010: Pesquisa Nacional de Saúde Bucal: resultados principais / Ministério da Saúde. Secretaria de Atenção à Saúde. Secretaria de Vigilância em Saúde. - Brasília: Ministério da Saúde, 2012. Disponível em: http://bvsms.saude.gov.br/bvs/publicacoes/ pesquisa_nacional_saude_bucal.pdf

BRASIL. Constituição Federal. Capítulo da Saúde, Brasília, 1988.

BRASIL. Lei Orgânica da Saúde. Brasília, 1990.

BROFFITT, B.; LEVY, S. M.; WARREN, J.; CAVANAUGH, J. E. Factors associated with surface-level caries incidence in children aged 9 to 13: the Iowa Fluoride Study. J. Public. Health Dent., 2013; 73(4): 304-10. Disponível em: https://www.ncbi.nlm.nih.gov/pmc/ articles/PMC5534239/

CAMPEZZATO, P. V. M.; NUNES, M. L. T. Atendimento em clínicas-escola de psicologia da região metropolitana de Porto Alegre. Estud. Psicol. (Campinas), v.24, n.1, p.3, 2007a. Campinas July/Sept. Disponível em: http://dx.doi.org/10.1590/ S0103-166X2007000300008.

CAMPEZZATO, P. V. M.; NUNES, M. L. T. Caracterização da Clientela da Clínica-Escola de Cursos de Psicologia da Região Metropolitana de Porto Alegre. p. 376-388, 2007b. Rio Grande do Sul. Disponível em: http: //pepsic.bvspsi.org.br/scielo.php?script=sci_artte xt\&pid=S000659432009000100010\&lng=pt \&nrm=isso.

KOBARG, A.; SACHETTI, V.; VIEIRA, M. (2006). Valores e crenças parentais: reflexões teóricas. Revista Brasileira de Crescimento e Desenvolvimento Humano, 16 (2), 96-102. Disponível em: htttp://pepsic.bvsalud.org/scielo.php?script=sci_arttext\&pid $=$ S0104-12822006000200010.

FIGUEIREDO, M. C.; ROSITO, D. B.; MICHAEL JÁ. Seven - year follow - up of na educative, preventive and restorative dental programo $f$ the baby clinic. JBP 1998; 1(2): $33-40$.

Fundação Instituto Brasileiro de Geografia e Estatística. Um panorama da saúde no Brasil: acesso e utilização de serviços, condições de saúde e fatores de risco e proteção à saúde, 2008: pesquisa nacional por amostra de domicílios. Rio de Janeiro: Instituto Brasileiro de Geografia e Estatística; 2010. Disponível em http://bvsms.saude.gov.br/bvs/ publicacoes/pnad_panorama_saude_brasil.pdf.

GUARIENTI, C. A.; BARRETO, V. C.; FIGUEIREDO, M. C. Conhecimento dos Pais e Responsáveis Sobre Saúde Bucal na Primeira Infância. Peq Bras Odontoped Clin Integr. 
2009; 9(3): 321-25. Disponível em; http://revista.uepb.edu.br/index.php/pboci/article/ download/743/397.

ISMAIL, A. I. Prevention of early childhood caries. Community Dent Oral Epidemiol, 1998; 26: 49-61. Disponível em: https://www.ncbi.nlm.nih.gov/pubmed/9671200.

JEON, J. G.; ROSALEN, P. L.; FALSETTA, M. L.; KOO, H. Natural products in caries research: current (limited) knowledge, challenges and future perspective. Caries Res. 2011; 45: 243-63. Disponível em: https://www.ncbi.nlm.nih.gov/pubmed/21576957

JUNIOR, J. L. A. L.; GONÇALVES, L. V.; CORREIA, A. A. Alimentos X Cárie: a ingestão do açúcar em excesso como fator estimulante do desenvolvimento da doença. Cadernos de Graduação, Ciências biológicas e da saúde | Recife | v. 2 | n. 2 | p. 11-20 | Dez 2015 | periodicos.set.edu.br. Disponível em: https://periodicos.set.edu.br/index.php/ facipesaude/article/view/3060.

KRAMER, P. F.; ARDENGHI, T. M. Utilização de serviços odontológicos por crianças de 0 a 5 anos de idade no município de Canela, Rio Grande do Sul, Brasil. Cad. Saúde Pública, vol.24, no.1, Rio de Janeiro Jan. 2008. Disponível em: http://www.scielo.br/scielo. php? script=sci_arttext\&pid=S0102-311X2008000100015.

MACARINI, S.; MARTINS, G.; MINETTO, M.; VIEIRA, M. (2010). Práticas parentais: uma revisão da literatura brasileira. Arquivos Brasileiros de Psicologia, 62(1), 119134. Disponível em: http://pepsic.bvsalud.org/scielo.php?script=sci_arttext\&pid $=$ S1809-52672010000100013.

MASSONI, A. C. L. T.; PAULO, S. F.; FORTE, F. D. S.; FREITAS, C. H. S. M.; SAMPAIO, F. C. Saúde Bucal Infantil: Conhecimento e Interesse de Pais e Responsáveis. Pesq Bras Odontoped Clin Integr. 2010; 10(2):257-64. Disponível em: https://edisciplinas.usp.br/ pluginfile.php/94256/mod_resource/content/1/artigo\%20trauma\%202.pdf.

Ministério da Educação. Secretaria de Educação Superior. Extensão Universitária: Organização e Sistematização. Política Nacional de Extensão. Universidade Federal de Minas Gerais. PROEX. COOPMED Editora, 2007. Disponível em: http://proex.ufpa.br/DIRETORIO/DOCUMENTOS/PROEX/00abertura.pdf

NAGARAJAPPA, R.; KAKATKAR, G.; SHARDA, A. J.; ASAWA, K.; RAMESH, G.; SANDESH, N. Infant oral health: knowledge, attitude and practices of parents in Udaipur, India. Dent Res J (Isfahan) 2013; 10(5):659-65. Disponível em: https://www.ncbi. nlm.nih.gov/pmc/articles/PMC3858743/

NAVARRO, M. L. R.; REYES, S. S.; ARAUJO, M. E. F.; ZAVALA, V. H. G.S. Prevalencia y grado de gingivitis asociada a placa dentobacteriana en niños. Revista Electrónica Nova Scientia, 2014; 6 (2) 190-218. Disponível em: http://www.scielo.org.mx/scielo. php?script=sci_arttext\&pid=S2007-07052014000200010

NOWAK AJ, QUIÑONEZ RB. Visionaries or dreamers? The story of infant oral health. Pediatr Dent, 2011; 33(2): 144-152. Disponível em: https://www.ncbi.nlm.nih.gov/ pubmed $/ 2170$ 
NUNES, E.; BRENDA, J. Manual para uma alimentação saudável em jardins de infância. Lisboa, Portugal: Direç̧ão Geral de Saúde, 2005. Disponível em: http://www.educacaotorresvedras.com/ficheiros/varios/manuel_para_alimentaa_aao_saudaavel_em_jis. pdf

OLIVEIRA, A. S. S.; UEMURA, T. F. Cárie dentária em crianças de um município da bahia e conhecimento dos seus responsáveis sobre saúde bucal. Rev. Saúde.Com 2016; 12(2): 535-541. Disponível em: http://www.uesb.br/revista/rsc/ojs/index.php/rsc/ article/view/355

PATROCÍNIO, M. C.; BORTOLIN, G. C. Avaliação do conhecimento dos pais em relação à saúde bucal de crianças institucionalizadas. ClipeOdonto 2014;6(1):18-27.

PELICIONI, C. A escola promotora de saúde. São Paulo: Faculdade de Saúde Pública da Universidade de São Paulo, 1999. p.12. (Séries Monográficas).

Pesquisa Nacional por Amostra de Domicílios. Acesso e Utilização de Serviços de Saúde. 1998. Brasil. Rio de Janeiro. 2000. Disponível em: https://ww2.ibge.gov.br/home/ estatistica/populacao/trabalhoerendimento/pnad98/saude/saude.pdf

REGO, T. Vygotsky: uma perspectiva histórico-cultural da educação. Rio de Janeiro: Vozes, 2011.

RIBEIRO, N. M. E.; RIBEIRO, M. A. S. Aleitamento materno e cárie do lactente e do pré-escolar: uma revisão crítica. J Pediatr (Rio J). 2004;80(5 Supl):S199-S210. Disponível em: http://www.scielo.br/pdf/jped/v80n5s0/v80n5s0a12.pdf

SABRINA DEMARI ET AL. Avaliação do conhecimento sobre higiene bucal dos responsáveis por crianças de 0-6 anos de idade. Faculdade de Odontologia de Lins/Unimep - 26(1) 11-18 • jan.-jun. 2016 ISSN Impresso: 0104-7582 • ISSN Eletrônico: 2238-1236.

SÁNCHEZ, O. M.; CHILDERS, N. K.; FOX, L.; BRADLEY, E. Physicians' views on pediatric preventive dental care. Pediatr Dent. 1997;19:377-83. Disponível em: https://www. ncbi.nlm.nih.gov/pubmed/9348601

SCALIONI, ALMEIDA RIBEIRO ET AL. Hábitos de dieta e cárie precoce da infância em crianças atendidas em faculdade de odontologia brasileira . Redalyc [on-line], 2012. Disponível em: http://revista.uepb.edu.br/index.php/pboci/article/viewFile/1352/880. Acesso em: 17 jul. 2015

SOARES, J.; VOLPATO, L. E. R.; CASTRO. P. H. C.; LAMBERT, N. A.; BORGES, A. H.; CARVALHOSA, A. A. Assessment of oral health knowledge of parents and caregivers of children and teens with disabilities. J Health Sci Inst. 2013;31(3):239-43. Disponível em: https://www.unip.br/presencial/comunicacao/publicacoes/ics/edicoes/2013_03.aspx

WIGEN, T. I.; WANG, N. J. Tooth brushing frequency and use of fluoride lozenges in children from 1.5 to 5 years of age: a longitudinal study. Community Dent. Oral Epidemiol, 2014; 42(5): 395-403. Disponível em: https://www.ncbi.nlm.nih.gov/ pubmed/24428413. 